\title{
Clinical features of severe patients infected with 2019 novel coronavirus: a systematic review and meta-analysis
}

\author{
Daozheng Huang ${ }^{1 \#}$, Xingji Lian ${ }^{2 \#}$, Feier Song ${ }^{3 \#}$, Huan Ma ${ }^{4}$, Zhiwen Lian ${ }^{5}$ Yuanfeng Liang ${ }^{6}$, Tiehe Qin ${ }^{1}$, \\ Wei Chen ${ }^{2}$, Shouhong Wang ${ }^{1}$
}

${ }^{1}$ Department of Critical Care Medicine, Guangdong Provincial People's Hospital, Guangdong Academy of Medical Sciences, Guangdong Provincial Geriatrics Institute, Guangzhou 510080, China; ${ }^{2}$ Department of Nephrology, The First Affiliated Hospital, Sun Yat-sen University, Key Laboratory of Nephrology, National Health Commission of China and Guangdong Province, Guangzhou 510080, China; ${ }^{3}$ Department of Emergency and Critical Care Medicine, Guangdong Provincial People's Hospital, Guangdong Academy of Medical Sciences, Guangzhou 510080, China; ${ }^{4}$ Guangdong Provincial Key Laboratory of Coronary Heart Disease Prevention, Guangdong Cardiovascular Institute, Guangdong Provincial People's Hospital, Guangdong Academy of Medical Sciences, Guangzhou 510080, China; ${ }^{5}$ Department of Nephrology, ${ }^{6}$ Department of Geriatrics, Guangdong Provincial Geriatrics Institute, Guangdong Provincial People's Hospital, Guangdong Academy of Medical Sciences, Guangzhou 510080, China

Contributions: (I) Conception and design: W Chen, S Wang, T Qin; (II) Administrative support: None; (III) Provision of study materials or patients: F Song, H Ma; (IV) Collection and assembly of data: F Song, H Ma, Z Lian, Y Liang; (V) Data analysis and interpretation: D Huang, X Lian, W Chen, S Wang; (VI) Manuscript writing: All authors; (VII) Final approval of manuscript: All authors.

\#The authors contributed equally to this work.

Correspondence to: Wei Chen, MD, PhD. Department of Nephrology, The First Affiliated Hospital, Sun Yat-sen University, Key Laboratory of Nephrology, National Health Commission of China and Guangdong Province, 58\# Zhongshan Road II, Guangzhou 510080, China. Email: vvchen66@qq.com; Shouhong Wang, MD. Department of Critical Care Medicine, Guangdong Provincial People’s Hospital, Guangdong Academy of Medical Sciences, Guangdong Provincial Geriatrics Institute, 106\# Zhongshan Road II, Guangzhou 510080, China. Email: wshdoctor@139.com.

Background: 2019 novel coronavirus disease (COVID-19) has posed significant threats to public health. To identify and treat the severe and critical patients with COVID-19 is the key clinical problem to be solved. The present study aimed to evaluate the clinical characteristics of severe and non-severe patients with COVID-19.

Methods: We searched independently studies and retrieved the data that involved the clinical characteristics of severe and non-severe patients with COVID-19 through database searching. Two authors independently retrieved the data from the individual studies, assessed the study quality with Newcastle-Ottawa Scale and analyzed publication bias by Begg's test. We calculated the odds ratio (OR) of groups using fixed or randomeffect models.

Results: Five studies with 5,328 patients confirmed with COVID-19 met the inclusion criteria. Severe patents were older and more common in dyspnea, vomiting or diarrhea, creatinine $>104 \mu \mathrm{mol} / \mathrm{L}$, procalcitonin $\geq 0.05 \mathrm{ng} / \mathrm{mL}$, lymphocyte count $<1.5 \times 10^{9} / \mathrm{L}$ and bilateral involvement of chest CT. Severe patents had higher risk on complications including acute cardiac injury (OR 13.48; 95\% CI, 3.60 to 50.47, $\mathrm{P}<0.001$ ) or acute kidney injury (AKI) (OR 11.55; 95\% CI, 3.44 to 38.77, $\mathrm{P}<0.001$ ), acute respiratory distress syndrome (ARDS) (OR 26.12; 95\% CI, 11.14 to 61.25, P<0.001), shock (OR 53.17; 95\% CI, 12.54 to 225.4, $\mathrm{P}<0.001)$ and in-hospital death (OR 45.24; 95\% CI, 19.43 to $105.35, \mathrm{P}<0.001)$. Severe group required more main interventions such as received antiviral therapy (OR 1.69; 95\% CI, 1.23 to 2.32, $\mathrm{P}=0.001$ ), corticosteroids (OR 5.07; 95\% CI, 3.69 to 6.98, P<0.001), CRRT (OR 37.95; 95\% CI, 7.26 to 198.41, $\mathrm{P}<0.001$ ) and invasive mechanical ventilation (OR 129.35; 95\% CI, 25.83 to 647.68, $\mathrm{P}<0.001$ ).

Conclusions: Severe patients with COVID-19 had more risk of clinical characteristics and multiple system organ complications. Even received more main interventions, severe patients had higher risk of mortality.

Keywords: 2019 novel coronavirus; acute respiratory disease; clinical features; disease severity; meta-analysis 
Submitted Mar 05, 2020. Accepted for publication Apr 07, 2020.

doi: $10.21037 /$ atm-20-2124

View this article at: http://dx.doi.org/10.21037/atm-20-2124

\section{Introduction}

A newly identified severe acute respiratory syndrome coronavirus 2 (SARS-CoV-2; previously been named as 2019 novel coronavirus or 2019-nCoV)-infected pneumonia (NCIP), which was also declared as 2019 novel coronavirus disease (COVID-19) from February 11, 2020, by the World Health Organization (WHO) (1), has strong ability of early human-to-human transmission $(2,3)$. COVID-19 has posed significant threats to public health since December 2019 (4). Thus far (as of 24:00 on February 11), more than 42,638 confirmed cases, including cumulative 1,016 death cases and 7,333 severe cases in total, have been identified throughout the whole of China (5). Internationally, quite a lot of cases have been confirmed in other countries. The WHO announced that the outbreak of the SARS-CoV-2 has become a Public Health Emergency of International Concern (PHEIC) (6). Unfortunately, the numbers of both infected patients and fatalities are still growing rapidly.

To identify and treat the severe and critical patients with COVID-19 bears on reducing the mortality, which is the key clinical problem to be solved. Several studies have described the clinical manifestations of affected patients with COVID-19 (4,7-10), and two studies $(4,7)$ also evaluated the difference on clinical characteristics between severe and non-severe cases. However, the sample size of these studies has been still insufficient to delineate the epidemiological severe cases. Recently, analysis with significantly larger sample sizes throughout China has been conducted to differentiate these cases (11) (preprint). Thus, the present study aimed to evaluate the clinical characteristics of severe and non-severe patients with COVID-19.

\section{Methods}

\section{Literature search strategy and inclusion criteria}

This study was performed according to the PRISMA recommendations and criteria for the reporting of metaanalysis guidelines (12). An electronic database search without language restrictions was systematically performed by two reviewers (DZH and XJL) in PubMed, Web of Science, MEDLINE, CNKI (China Knowledge Resource Integrated Database) and the Cochrane Central Register of
Controlled Trials (CENTRAL) from December 1, 2019, to February 12, 2020. In addition, we also sought ongoing and unpublished trials through ClinicalTrials.gov. Studies that involved clinical characteristics between severe and non-severe patients with COVID-19 were included. The search terms included the following: "2019-nCoV", "Novel Coronavirus", "2019 Novel Coronavirus", "COVID-19”.

The included studies had to meet the following criteria: (I) clinical trials including the cohort or case-control or descriptive studies; (II) human studies involved identified COVID-19 patients; (III) contained the information on clinical characteristics of patients with COVID-19. Patients who were admitted to ICU and non-ICU were also categorized into a severe and non-severe subgroup. We also included the studies which were preprint. If the studies focused on pregnant patients and other coronaviruses, such as the Middle East respiratory syndrome (MERS) or severe acute respiratory syndrome (SARS) human coronavirus, they were excluded. In addition, studies lacking the information on grouping between severe and non-severe patients were also excluded after attempting to obtain the data from the authors.

\section{Data extraction and quality evaluation}

Two independent reviewers conducted the data extraction and checked by each other (FES and FM). When there were disagreements, they resolved through discussion. For each included study, a record of the first author, publication date, number of patients, mean age, the proportion of males, smoking status and history of exposure to the market of the participant were extracted. We mainly focused on the clinical characteristics including symptoms and signs (fever, vomiting, diarrhea, headache, myalgia), laboratory indicators (creatinine, white blood cell count, procalcitonin), bilateral involvement of chest CT, complications [acute respiratory distress syndrome (ARDS), acute cardiac injury, acute kidney injury (AKI), shock], treatment [antiviral therapy, use of corticosteroid, continuous renal replacement therapy (CRRT), oxygen support], and in-hospital death.

We evaluated all included literature using the NewcastleOttawa Scale (NOS) (13). In this study, two investigators (ZWL and YFL) conducted the assessment scores for 


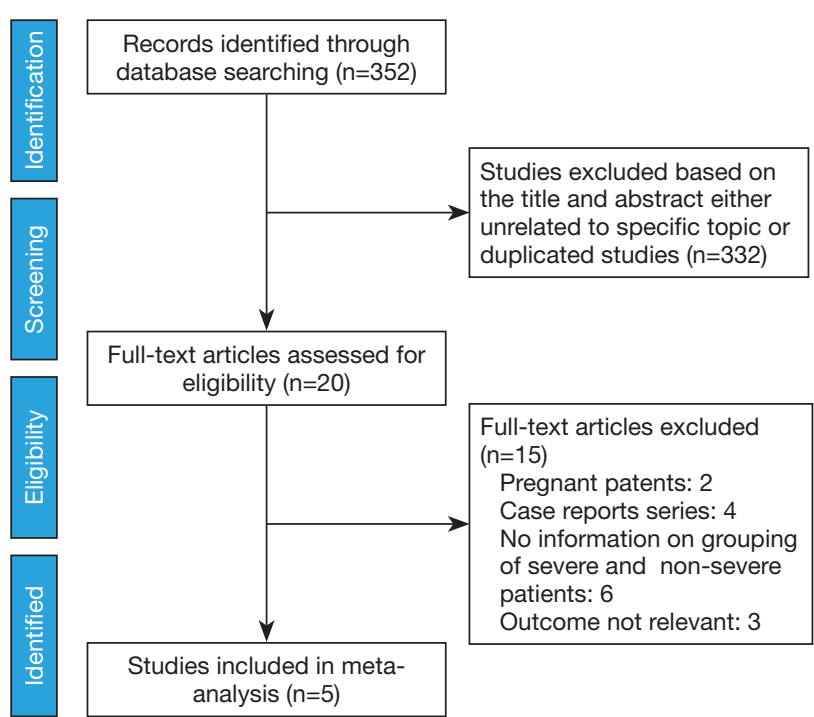

Figure 1 Flow chart for the selection of studies.

quality of each included study, of which a maximum of 1 point for each item in the selection and exposure perspectives and a maximum of 2 points in comparability. They also resolved the discrepancies by consensus. If they could not reach a consensus, other investigators helped to make a final decision through a vote majority.

\section{Statistical analysis}

We used the odds ratio (OR) with $95 \%$ confidence interval (CI) for the dichotomous outcomes and weighted mean difference (MD) with $95 \%$ CI for the continuous outcomes. To determine the between-study heterogeneity, we used Cochran's $Q$ test $(P>0.10$ for statistical significance) and $\mathrm{I}^{2}$ test (considered $\mathrm{I}^{2}$ values $<25 \%$ to represent low heterogeneity, 25-50\% to moderate heterogeneity, and $>50 \%$ to severe heterogeneity). A fixedeffects model was applied if there was minimal significant heterogeneity, while the random-effects model was used if moderate to severe heterogeneity. To examine the possibility of publication bias, Funnel plots and Begg's tests were generated. Begg's test with $\mathrm{P}>0.1$ was considered as no publication bias. Leave-one-out sensitivity analysis was also performed to evaluate the robustness of the results. A two-tailed $\mathrm{P}$ value $<0.05$ was considered significant. We used Review Manager version 5.3 (The Nordic Cochrane Centre, Copenhagen, Denmark) and Stata version 14 (Stata Corp LP, College Station, TX, USA) to perform the meta-analysis and produce the graph.

\section{Results}

\section{Characteristics of the included studies}

Literature searches identified and screened 352 potential abstracts, of which 20 underwent a full-text review. Of these, 15 studies were excluded for the following reasons: pregnant patients, case reports, no information on the grouping of severe and non-severe patients and irrelevant outcome. Consequently, 5 studies $(4,7,11,14,15)$ met the inclusion criteria and entered final meta-analysis (Figure 1), of which 2 studies were preprint $(11,15)$. A total of 5,328 patients (4,972 patients contained the information of disease severity) with confirmed COVID-19 in 5 studies were from China, with a mean/median age of between 47 and 56 years. Other information was listed in the table of characteristics of included studies (Table 1). In addition, all included studies were of high quality with a NOS score $\geq 6$ (Table 2).

\section{Presenting clinical characteristics}

On admission, a total of 1,171 and 3,801 patients were categorized into severe and non-severe subgroups, respectively. Studies from Yang et al. (15) and Chen et al. (14) lacked some information of characteristics. Patents in severe group were 8.87 years more than those in non-severe group in a random-effects model (MD 8.87; 95\% CI, 5.42 to $12.32, \mathrm{P}<0.001)$, with severe heterogeneity $\left(\mathrm{I}^{2}=71 \%\right.$, $\mathrm{P}=0.01)$. There were no significant differences between the two groups regarding the gender (OR 1.29; 95\% CI, 0.99 to $\left.1.67, \mathrm{P}=0.06 ; \mathrm{I}^{2}=39 \%, \mathrm{P}=0.18\right)$. For signs and symptoms, there was a statistically significance on higher risk of dyspnea (OR 5.50; 95\% CI, 2.45 to $12.33, \mathrm{P}<0.001 ; \mathrm{I}^{2}=61 \%$, $\mathrm{P}=0.08)$ and gastrointestinal symptoms including vomiting and diarrhea (OR 1.86; 95\% CI, 1.19 to $2.89, \mathrm{P}=0.006$; $\left.\mathrm{I}^{2}=0 \%, \mathrm{P}=0.47\right)$ in the severe group than non-severe group. However, there were no significant differences between the two groups regarding the headache (OR 1.17; 95\% CI, 0.77 to $1.78, \mathrm{P}=0.46$ ), fever (OR $1.25 ; 95 \% \mathrm{CI}, 0.91$ to 1.73 , $\mathrm{P}=0.17$ ), myalgia or arthralgia (OR $1.20 ; 95 \% \mathrm{CI}, 0.83$ to 1.74, $\mathrm{P}=0.32$ ), with minimal heterogeneity. For laboratory findings, patents in severe group had higher risk compared to those in non-severe group on procalcitonin $\geq 0.05 \mathrm{ng} / \mathrm{mL}$ (OR 6.92; 95\% CI, 3.02 to $15.86, \mathrm{P}<0.001 ; \mathrm{I}^{2}=42 \%$, $\mathrm{P}=0.18$ ), creatinine $>104 \mu \mathrm{mol} / \mathrm{L}$ (OR 2.90; 95\% CI, 1.16 to $\left.7.26, \mathrm{P}=0.02 ; \mathrm{I}^{2}=0 \%, \mathrm{P}=0.47\right)$ and lymphocyte count $<1.5 \times 10^{9} / \mathrm{L}$ (OR 4.39; $95 \%$ CI, 3.06 to $6.30, \mathrm{P}<0.001$; $\left.\mathrm{I}^{2}=0 \%, \mathrm{P}=0.92\right)$. However, there were no significant differences between the two groups regarding the blood 


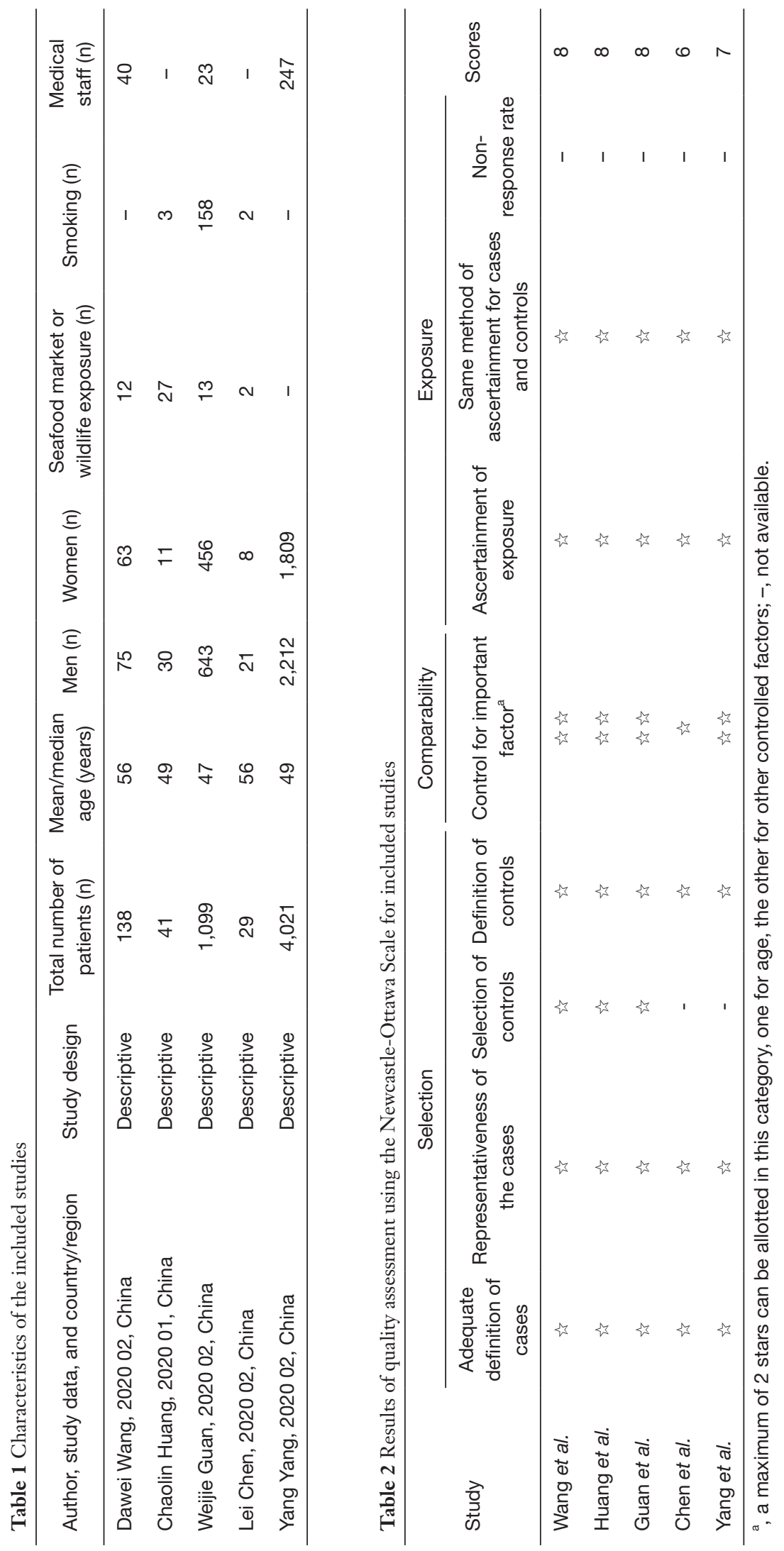


white leukocyte count $<4 \times 10^{9} / \mathrm{L}$ (OR 1.02; $95 \%$ CI, 0.05 to $22.09, \mathrm{P}=0.99)$, with severe heterogeneity $\left(\mathrm{I}^{2}=87 \%\right.$, $\mathrm{P}=0.005)$. Patents in severe group had higher risk compared to those in non-severe group on bilateral involvement of chest CT (OR 5.66; 95\% CI, 3.84 to $8.34, \mathrm{P}<0.001 ; \mathrm{I}^{2}=0 \%$, $\mathrm{P}=0.42$ ) (Figures S1-S12).

\section{Complications and death}

Patents in severe group had higher risk on the incidence of acute cardiac injury (OR 13.48; $95 \%$ CI, 3.60 to 50.47 , $\mathrm{P}<0.001$ ) or AKI (OR $11.55 ; 95 \%$ CI, 3.44 to 38.77 , $\mathrm{P}<0.001$ ), ARDS (OR 26.12; 95\% CI, 11.14 to 61.25 , $\mathrm{P}<0.001$ ), and shock (OR 53.17; 95\% CI, 12.54 to 225.4, $\mathrm{P}<0.001)$ than non-severe group. For in-hospital death, there was a statistically significance of higher risk in severe group (OR 45.24; 95\% CI, 19.43 to $105.35, \mathrm{P}<0.001$; $\left.\mathrm{I}^{2}=0 \%, \mathrm{P}<0.60\right)$. The results all were with minimal heterogeneity (Figure 2).

\section{Main interventions}

Patents in severe group had higher risk on the received antiviral therapy (OR 1.69; 95\% CI, 1.23 to 2.32, $\mathrm{P}=0.001$ ), corticosteroids (OR 5.07; 95\% CI, 3.69 to $6.98, \mathrm{P}<0.001$ ), CRRT (OR 37.95; 95\% CI, 7.26 to $198.41, \mathrm{P}<0.001$ ) than non-severe group, with minimal heterogeneity. In addition, invasive mechanical ventilation (OR 129.35; 95\% CI, 25.83 to $\left.647.68, \mathrm{P}<0.001, \mathrm{I}^{2}=23 \%, \mathrm{P}=0.27\right)$ and noninvasive mechanical ventilation (OR 119.75; 95\% CI, 9.22 to $\left.1,556.24, \mathrm{P}<0.001, \mathrm{I}^{2}=69 \%, \mathrm{P}=0.04\right)$ was more required in severe group than non-severe group (Figure 3).

\section{Examination of the funnel plot}

There was no apparent systematic publication bias among the included trials according to the result of Begg's test $(\mathrm{P}=0.69)$ for in-hospital death. The funnel plot was relatively symmetrical (Figure 4). However, there were inevitably publication bias if the number of included studies were small.

\section{Discussion}

The present meta-analysis and systematic review mainly described the clinical characteristics of severe patients with COVID-19. We considered data from clinical characteristics, complications and main interventions between severe and non-severe patients, allowing better targeting of the population of interest.

The definition and classification of COVID-19 were in accordance with the selected articles, respectively. They were referred to the WHO interim guidance (16) or the standard protocol issued by the National Health Commission of the People's Republic of China (17). From the 5 selected articles, a large set of clinical indices were assessed, showing both the large panel of clinical symptoms and laboratory features could be considered clinical signs for prediction and diagnosis of severe COVID-19. The symptoms of the COVID-19 were non-specific. Fever was the most frequently assessed clinical signs. However, no significance was found for gender, fever, myalgia or arthralgia, headache and blood leukocyte count $<4 \times 10^{9} / \mathrm{L}$ of severe cases compared to non-severe cases. To note, the recent report revealed COVID-19 was more prone to male patients (18), while the present study was difficult to differentiate the gender between severe and nonsevere patients. Based on the data, we found age, dyspnea, vomiting or diarrhea, creatinine $>104 \mu \mathrm{mol} / \mathrm{L}$, procalcitonin $\geq 0.05 \mathrm{ng} / \mathrm{mL}$, lymphocyte count $<1.5 \times 10^{9}$ and bilateral involvement of chest CT to be significantly associated with severe cases. However, the heterogeneity of the dyspnea and procalcitonin $\geq 0.05 \mathrm{ng} / \mathrm{mL}$ was apparent and we performed the leave-one-out sensitivity analysis to evaluate the robustness of the results, of which a study from Guan et al. (11) had a more prominence. The study also showed severe cases had more proportion of dyspnea and procalcitonin $\geq 0.05 \mathrm{ng} / \mathrm{mL}$ as compared with non-severe cases (11). Recent studies found SARS-CoV-2 induced diarrhea as onset symptom in a patient with COVID-19 (without high fever, cough, dyspnea and chest pain) (19) and SARS-CoV-2 could be found in stool samples of patients with abdominal symptoms (20), which increased the evidence for gastrointestinal infection of SARS-CoV-2 and spreading through fecal oral route. Therefore, diarrhea should not be underestimated and the digestive system for severe patients should be paid more attention to. In terms of laboratory tests, the reduced absolute value of lymphocyte may be a common feature of patients with COVID-19. A recent pathological finding of COVID-19 associated with ARDS indicated lymphocytopenia may be a key factor associated with disease severity and mortality (21). The present study suggests that SARS-CoV-2 might more act on lymphocytes in severe patients, which indicated damage to $\mathrm{T}$ lymphocytes might be an important factor leading to exacerbations of patients (21). Pan et al. demonstrated that 
Acute cardiac injury

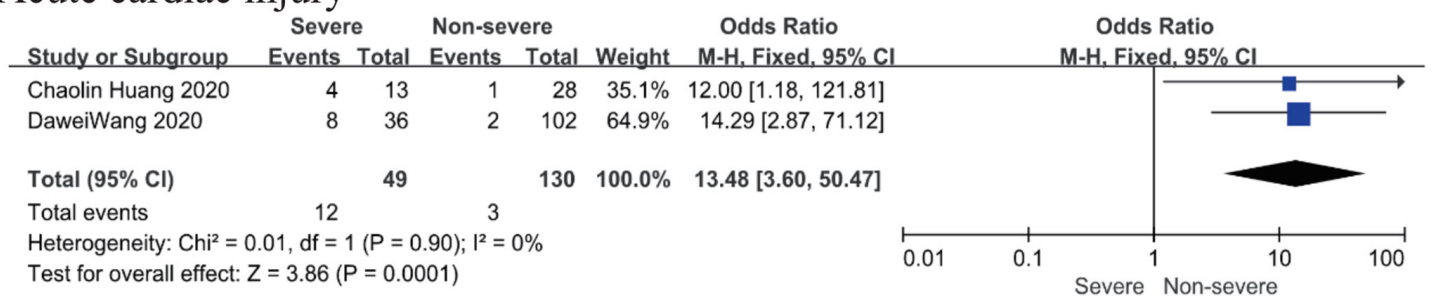

Acute kidney injury

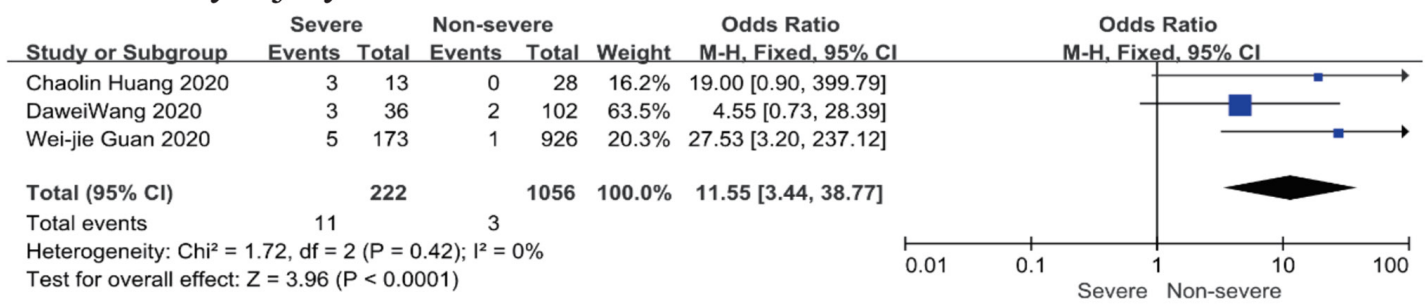

Acute respiratory distress syndrome

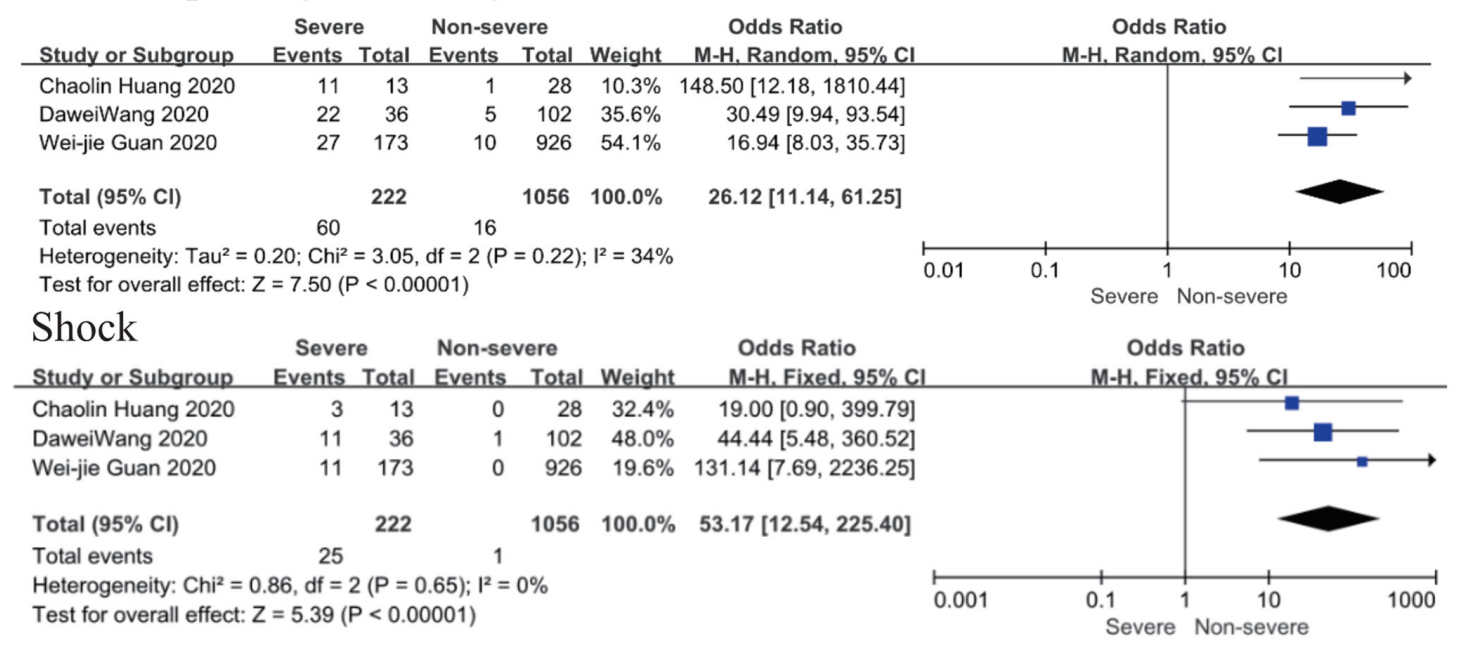

In-hospital death

\begin{tabular}{|c|c|c|c|c|c|c|c|c|c|}
\hline Study or Subgroup & $\begin{array}{l}\text { Sever } \\
\text { Events }\end{array}$ & Total & $\begin{array}{l}\text { Non-sev } \\
\text { Events }\end{array}$ & $\begin{array}{l}\text { vere } \\
\text { Total }\end{array}$ & Weight & $\begin{array}{l}\text { Odds Ratio } \\
\text { M-H. Fixed. } 95 \% \mathrm{Cl}\end{array}$ & $\begin{array}{r}\text { Odds } \\
\text { M-H. Fixe }\end{array}$ & $\begin{array}{l}\text { Ratio } \\
\text { ed. } 95 \% \mathrm{Cl}\end{array}$ & \\
\hline Chaolin Huang 2020 & 5 & 13 & 1 & 28 & $14.2 \%$ & $16.88[1.71,166.21]$ & & $\longrightarrow$ & \\
\hline Chen Lei 2020 & 2 & 14 & 0 & 15 & $14.7 \%$ & $6.20[0.27,141.32]$ & & & \\
\hline DaweiWang 2020 & 6 & 36 & 0 & 102 & $7.9 \%$ & $43.69[2.39,797.75]$ & & & \\
\hline Wei-jie Guan 2020 & 14 & 173 & 1 & 926 & $10.6 \%$ & $81.45[10.64,623.70]$ & & & \\
\hline Yang Yang 2020 & 55 & 935 & 3 & 2730 & $52.6 \%$ & $56.81[17.73,182.05]$ & & & \\
\hline Total $(95 \% \mathrm{Cl})$ & & 1171 & & 3801 & $100.0 \%$ & $45.24[19.43,105.35]$ & & & \\
\hline Total events & 82 & & 5 & & & & & & \\
\hline \multicolumn{5}{|c|}{$\begin{array}{l}\text { Heterogeneity: } \mathrm{Chi}^{2}=2.73, \mathrm{df}=4(P=0.60) ;\left.\right|^{2}=0 \% \\
\text { Test for overall effect: } Z=8.84(P<0.00001)\end{array}$} & & 0.001 & ${ }^{0.1}{ }^{1}$ & $\begin{array}{cc}1 & 10 \\
& \text { Non-sever }\end{array}$ & 1000 \\
\hline
\end{tabular}

Figure 2 Forest plots of comparison severe versus non-severe cases for complications. 
Antiviral therapy

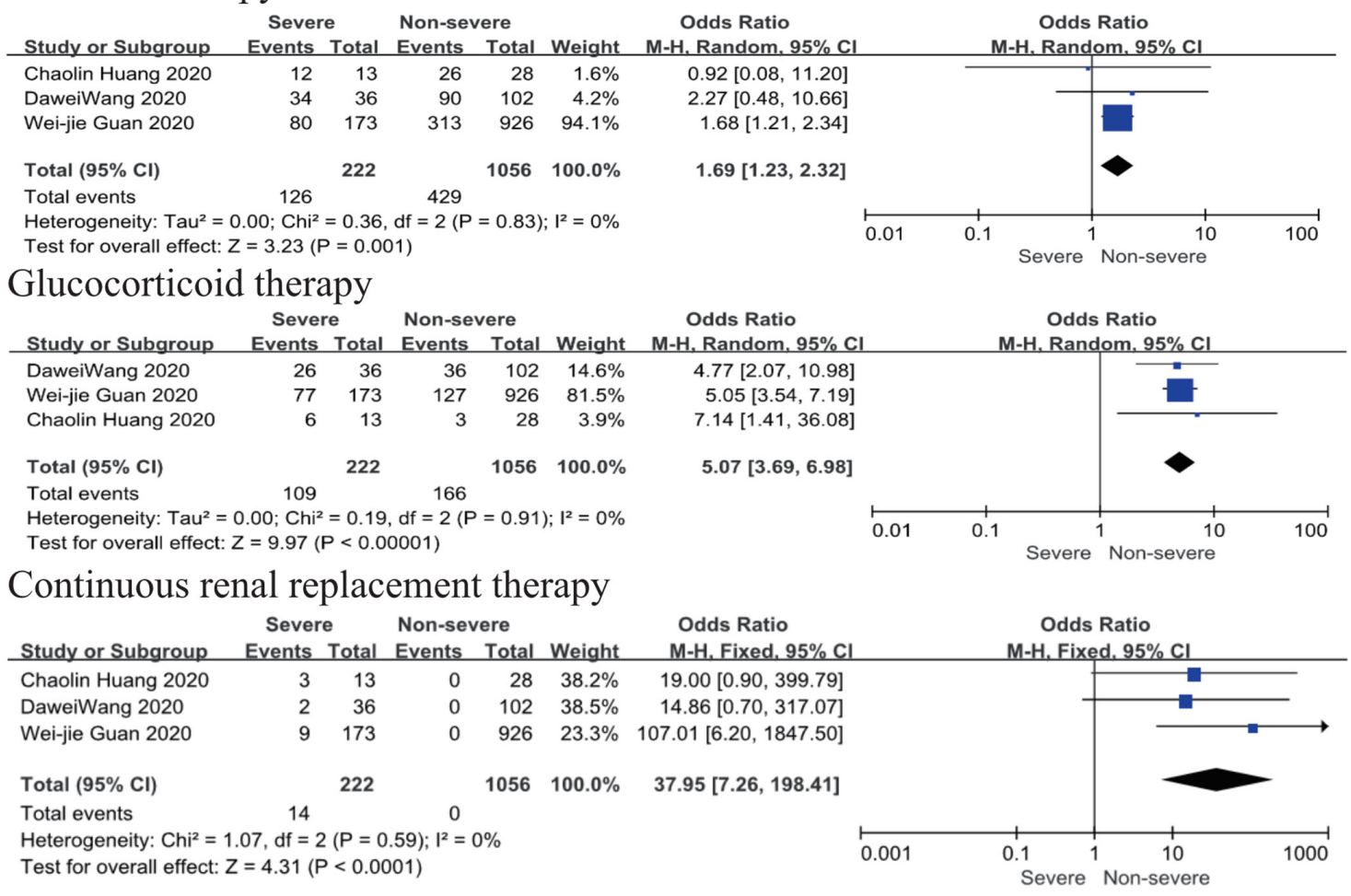

\section{Invasive mechanical ventilation}

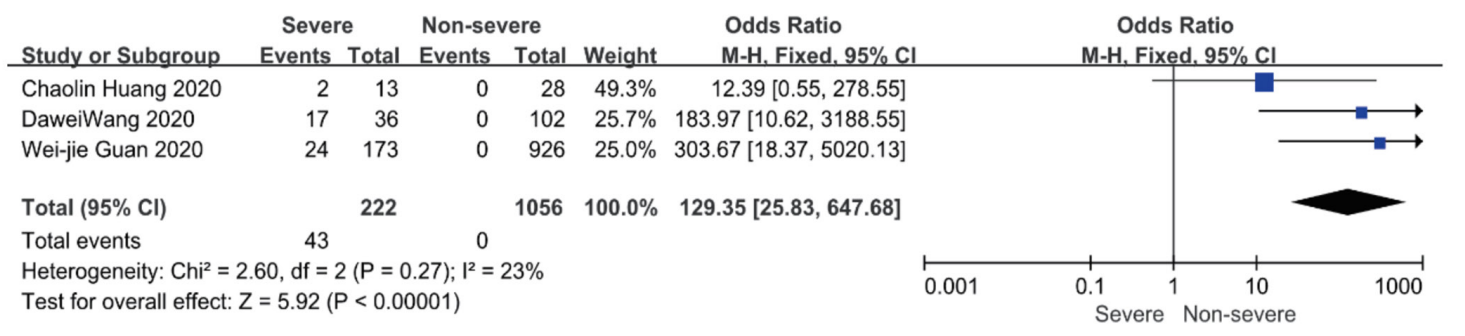

Noninvasive mechanical ventilation

\begin{tabular}{|c|c|c|c|c|c|c|c|c|c|c|}
\hline Study or Subgroup & $\begin{array}{l}\text { Sever } \\
\text { Events }\end{array}$ & Total & $\begin{array}{l}\text { Non-sev } \\
\text { Events }\end{array}$ & $\begin{array}{l}\text { Iere } \\
\text { Total }\end{array}$ & Weight & $\begin{array}{l}\text { Odds Ratio } \\
\text { M-H, Random, } 95 \% \mathrm{Cl}\end{array}$ & & $\begin{array}{r}\text { Odds } \\
M-H, \text { Rand }\end{array}$ & $\begin{array}{l}\text { Ratio } \\
\text { dom, } 95 \% \mathrm{Cl}\end{array}$ & \\
\hline Chaolin Huang 2020 & 8 & 13 & 2 & 28 & $38.9 \%$ & $20.80[3.37,128.54]$ & & & $\longrightarrow$ & \\
\hline DaweiWang 2020 & 15 & 36 & 0 & 102 & $30.3 \%$ & $147.79[8.51,2565.93]$ & & & & \\
\hline Wei-jie Guan 2020 & 56 & 173 & 0 & 926 & $30.8 \%$ & $891.02[54.69,14516.15]$ & & & & \\
\hline Total $(95 \% \mathrm{Cl})$ & & 222 & & 1056 & $100.0 \%$ & $119.75[9.22,1556.24]$ & & & & \\
\hline Total events & 79 & & 2 & & & & & & & \\
\hline $\begin{array}{l}\text { Heterogeneity: } \mathrm{Tau}^{2}= \\
\text { Test for overall effect: }\end{array}$ & $\begin{array}{l}.53 ; \mathrm{Chi}^{2} \\
=3.66(\mathrm{P}\end{array}$ & $\begin{array}{l}=6.49, \\
=0.00\end{array}$ & $\begin{array}{l}d f=2(P \\
003)\end{array}$ & $=0.04)$ & $; 1^{2}=69 \%$ & & 0.001 & 0.1 & $10 \frac{10}{\text { Non-severe }}$ & 1000 \\
\hline
\end{tabular}

Figure 3 Forest plots of comparison severe versus non-severe cases for main interventions. 


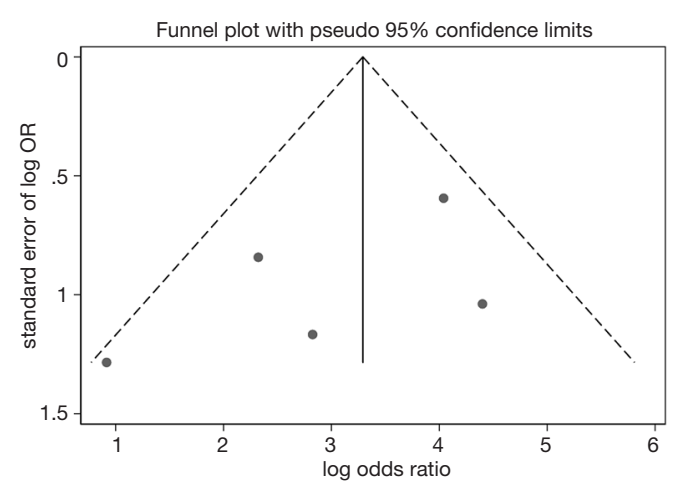

Figure 4 Funnel plot with $95 \%$ confidence interval (CI) to assess publication bias.

the manifestations of the new coronavirus pneumonia are diverse (22). At an early stage, patients may have a single lobe or multiple lobes involvement, but as the disease progressed, the lungs showed diffuse lesions, and the density of both lungs increased widely in the short-term. The present study showed bilateral involvement of chest was an indicator of severe case, which helps early diagnosis based on imaging findings.

A study using single-cell RNA-seq data analysis showed that the receptor ACE2 (angiotensin-converting enzyme II) as a cell entry receptor, expression in lung, esophagus, kidney, bladder, and ileum were as high as respiratory organs (lung). This result suggested that the multiple organs could be affected by COVID-19 (23), which may lead to the complications of ARDS, AKI, acute cardiac injury and shock. To note, the present study showed severe cases had a higher risk of acute cardiac injury (OR 13.48; $95 \%$ CI, 3.60 to $50.47, \mathrm{P}<0.001)$. A study of 99 hospitalized patients with confirmed COVID-19 showed $40 \%$ of patients have a cardiovascular or cerebrovascular disease (18). However, pathological characteristics of biopsy samples from a patient who died from severe infection with SARS found no obvious histological changes in heart tissue, indicating that SARS-CoV-2 infection might not directly impair the heart (21). The association between COVID-19 and cardiac injury requiring further confirmed. According to the clinical guidance of COVID-19 from American College of Cardiology, it is advisable for patients with underlying cardiovascular disease of the potential increased risk to encourage additional and reasonable precautions and the medical staffs tailored guideline-directed therapies to individual patients in geographies with active COVID-19 transmission (24). Severe cases had a significantly higher risk of progressed rapidly with complications, which was eventually followed by multiple organs failure. A report on the epidemiological and clinical outcomes of 41 laboratoryconfirmed cases infected with COVID-19 showed higher concentrations of GCSF, MIP1A, IP10, MCP1, and TNFa in patients who required ICU admission than those not requiring ICU admission, suggesting that the cytokine storm was related to disease severity (4). Thus, it may be of great significance to initiate the blood purification therapy (such as plasma exchange, immunoadsorption or CRRT) for the purpose of eliminating cytokines in the early stage, which have been previous demonstrated to play an important role on SARS, MERS and other sepsis treatment $(25,26)$.

Patents in the severe group had higher risk on the received antiviral and corticosteroids therapy, as well as CRRT and invasive mechanical ventilation than the nonsevere group. However, for in-hospital death, there was a statistically significantly higher risk in the severe group. The reasons could be as follow. Firstly, until now, no specific treatment or antiviral agents have enough evidence to be recommended for treating COVID-19 infection. No unique clinical evidence exists to expect that patients with COVID-19 will benefit from corticosteroids (27). In addition, critically ill cases had a higher risk of progressing rapidly with ARDS, AKI, acute cardiac injury, and shock, leading to a higher possibility of death. Therefore, it might still be useful to identify cases that are at risk of admission to ICU and would benefit from critical care rather than merely oxygen therapy plus the provision of antiviral drugs.

There are several limitations of this study. Firstly, only a few articles with limited sample sizes were found, and all of them were observational studies and two studies were preprint, which may affect the quality of the present study. Secondly, non-severe cases that were not admitted to the hospital were ruled out in the analyses. This inclusion might have biased the discriminative value of measures for severe cases. Thirdly, since we have found no related studies focusing on patients of other races, the demonstration of the effect of the present study was limited to Chinese patients with COVID-19. Fourthly, some date on the grouping of severe and non-severe cases were missing because they were not measured or no reported in the included studies, which may lead to a lack of power or selective outcome reporting. Finally, although the funnel plots and Begg's test did not show publication bias, we could not rule out the possibility of publication bias as the number of included studies were small. However, the data in this study permit an early 
assessment of the clinical and laboratory characteristics to predict severe cases of COVID-19.

\section{Conclusions}

Severe patients with COVID-19 had more risk of clinical characteristics (age, dyspnea, vomiting or diarrhea, creatinine $>104 \mu \mathrm{mol} / \mathrm{L}$, procalcitonin $\geq 0.05 \mathrm{ng} / \mathrm{mL}$, lymphocyte count $<1.5 \times 10^{9} / \mathrm{L}$ and bilateral involvement of chest CT) and multiple system organ complications (acute cardiac injury, ARDS, AKI, and shock). Even received more main interventions (antiviral and corticosteroids therapy, as well as CRRT and invasive mechanical ventilation), the mortality was extremely higher in severe patients than nonsevere cases. Early identification and efforts to explore effective therapy for critically ill cases are a crucial concern.

\section{Acknowledgments}

Funding: WC reports grants from Chinese National Key Technology R and D Program, Ministry of Science and Technology, grants from National Natural Science Foundation of China, grants from Guangzhou Municipal Program of Science and Technology, grants from Key Laboratory of National Health Commission, and Key Laboratory of Nephrology, Guangdong Province, Guangzhou, China, during the conduct of the study. SW reports grants from National Clinical Key Specialty Construction Project of China, grants from Medical Scientific Research Foundation of Guangdong Province, during the conduct of the study. This work was supported by grants from the Chinese National Key Technology R and D Program, Ministry of Science and Technology (No. 2017YFC0907601, No. 2017YFC0907602, and No. 2017YFC0907603, No. 2016YFC0906100, No. 2016YFC0906101 to WC); National Natural Science Foundation of China (No. 81970599 to WC); Guangzhou Municipal Program of Science and Technology (No. 201804020049 to WC); Key Laboratory of National Health Commission, and Key Laboratory of Nephrology, Guangdong Province, Guangzhou, China (No. 2002B60118, 2017B030314019 to WC); National Clinical Key Specialty Construction Project of China (2012-649, 2013-544 to SHW); Medical Scientific Research Foundation of Guangdong Province (A2018064 to DZH).

\section{Footnote}

Conflicts of Interest: All authors have completed the ICMJE uniform disclosure form (available at http://dx.doi. org/10.21037/atm-20-2124). The authors have no conflicts of interest to declare.

Ethical Statement: The authors are accountable for all aspects of the work in ensuring that questions related to the accuracy or integrity of any part of the work are appropriately investigated and resolved.

Open Access Statement: This is an Open Access article distributed in accordance with the Creative Commons Attribution-NonCommercial-NoDerivs 4.0 International License (CC BY-NC-ND 4.0), which permits the noncommercial replication and distribution of the article with the strict proviso that no changes or edits are made and the original work is properly cited (including links to both the formal publication through the relevant DOI and the license). See: https://creativecommons.org/licenses/by-nc-nd/4.0/.

\section{References}

1. WHO. WHO convenes meeting of top scientists to slow coronavirus spread. Disease outbreak news. (Feb 11, 2020, Accessed Feb 17, 2020). Available online: https://www. who.int/emergencies/diseases/novel coronavirus-2019

2. Chan JF, Yuan S, Kok KH, et al. A familial cluster of pneumonia associated with the 2019 novel coronavirus indicating person-to-person transmission: a study of a family cluster. Lancet 2020;395:514-23.

3. Li Q, Guan X, Wu P, et al. Early Transmission Dynamics in Wuhan, China, of Novel Coronavirus-Infected Pneumonia. N Engl J Med 2020;382:1199-207.

4. Huang C, Wang Y, Li X, et al. Clinical features of patients infected with 2019 novel coronavirus in Wuhan, China. Lancet 2020;395:497-506.

5. National Health Commission of the People's Republic of China. Available online: http://www.nhc.gov.cn (Assessed on February 6 th , 2020).

6. WHO. International Health Regulations Emergency Committee on novel coronavirus in China. Newsroom. (Accessed Jan 30, 2020). Available online: https://www. who.int/news-room/events/detail/2020/01/30/defaultcalendar/international-health-regulations-emergencycommittee-on-novel-coronavirus-in-china

7. Wang D, Hu B, Hu C, et al. Clinical Characteristics of 138 Hospitalized Patients With 2019 Novel CoronavirusInfected Pneumonia in Wuhan, China. JAMA 2020. [Epub ahead of print]. 
8. Chen N, Zhou M, Dong X, et al. Epidemiological and clinical characteristics of 99 cases of 2019 novel coronavirus pneumonia in Wuhan, China: a descriptive study. Lancet 2020;395:507-13.

9. Wang W, Tang J, Wei F. Updated understanding of the outbreak of 2019 novel coronavirus $(2019-\mathrm{nCoV})$ in Wuhan, China. J Med Virol 2020;92:441-7.

10. Chang D, Lin M, Wei L, et al. Epidemiologic and Clinical Characteristics of Novel Coronavirus Infections Involving 13 Patients Outside Wuhan, China. JAMA 2020. [Epub ahead of print].

11. Guan WJ, Ni ZY, Hu Y, et al. Clinical characteristics of 2019 novel coronavirus infection in China. N Engl J Med doi: 10.1056/NEJMoa2002032.

12. Hutton B, Salanti G, Caldwell DM, et al. The PRISMA extension statement for reporting of systematic reviews incorporating network meta-analyses of health care interventions: checklist and explanations. Ann Intern Med 2015;162:777-84.

13. Stang A. Critical evaluation of the Newcastle-Ottawa scale for the assessment of the quality of nonrandomized studies in meta-analyses. Eur J Epidemiol 2010;25:603-5.

14. Chen L, Liu HG, Liu W, et al. Analysis of clinical features of 29 patients with 2019 novel coronavirus pneumonia. Zhonghua Jie He He Hu Xi Za Zhi 2020;43:E005.

15. Yang Y, Lu Q, Liu M, et al. Epidemiological and clinical features of the 2019 novel coronavirus outbreak in China. medRxiv 2020:2020.02.10.20021675.

16. WHO. Clinical management of severe acute respiratory infection when novel coronavirus infection is suspected: interim guidance. Published January 28, 2020. Accessed January 31, 2020.

17. National Health Commission of the People's Republic of China. Diagnosis and treatment ofpneumonia infected with novel coronavirus. 2020. Available online: http:// www.nhc.gov.cn/yzygj/s7653p/202001/f492c9153ea9437b b587ce2ffcbee1fa.shtml

Cite this article as: Huang D, Lian X, Song F, Ma H, Lian Z, Liang Y, Qin T, Chen W, Wang S. Clinical features of severe patients infected with 2019 novel coronavirus: a systematic review and meta-analysis. Ann Transl Med 2020;8(9):576. doi: 10.21037/atm-20-2124
18. Chen N, Zhou M, Dong X, et al. Epidemiological and clinical characteristics of 99 cases of 2019 novel coronavirus pneumonia in Wuhan, China: a descriptive study. Lancet 2020;395:507-13.

19. Song Y, Liu P, Shi XL, et al. SARS-CoV-2 induced diarrhoea as onset symptom in patient with COVID-19. Gut 2020. [Epub ahead of print].

20. Zhang H, Kang Z, Gong H, et al. The digestive system is a potential route of 2019-nCov infection: a bioinformatics analysis based on single-cell transcriptomes. BioRxiv 2020. doi: 10.1101/2020.01.30.927806.

21. Xu Z, Shi L, Wang Y, et al. Pathological findings of COVID-19 associated with acute respiratory distress syndrome. Lancet Respir Med 2020;8:420-2.

22. Pan Y, Guan H, Zhou S, et al. Initial CT findings and temporal changes in patients with the novel coronavirus pneumonia (2019-nCoV): a study of 63 patients in Wuhan, China. Eur Radiol 2020. [Epub ahead of print].

23. Zou X, Chen K, Zou J, et al. Single-cell RNA-seq data analysis on the receptor ACE2 expression reveals the potential risk of different human organs vulnerable to 2019-nCoV infection. Front Med 2020. [Epub ahead of print].

24. Madjid M. ACC Clinical Bulletin: Cardiac Implications of Novel Wuhan Coronavirus (2019-nCoV). Accessed Feb 13, 2020.

25. Chu KH, Tsang WK, Tang CS, et al. Acute renal impairment in coronavirus-associated severe acute respiratory syndrome. Kidney Int 2005;67:698-705.

26. Arabi YM, Arifi AA, Balkhy HH, et al. Clinical course and outcomes of critically ill patients with Middle East respiratory syndrome coronavirus infection. Ann Intern Med 2014;160:389-97.

27. Russell CD, Millar JE, Baillie JK. Clinical evidence does not support corticosteroid treatment for 2019-nCoV lung injury. Lancet 2020;395:473-5. 


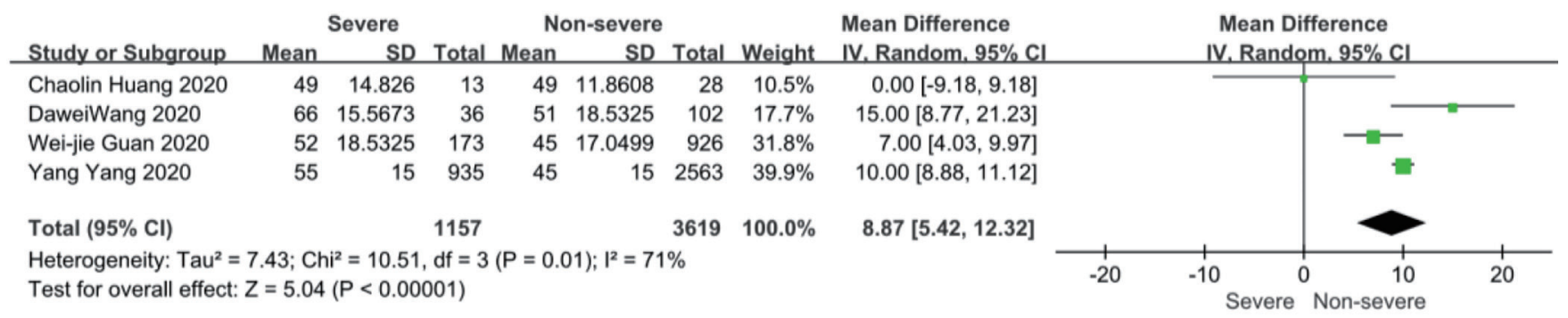

Figure S1 Forest plots of comparison severe versus non-severe cases for age.

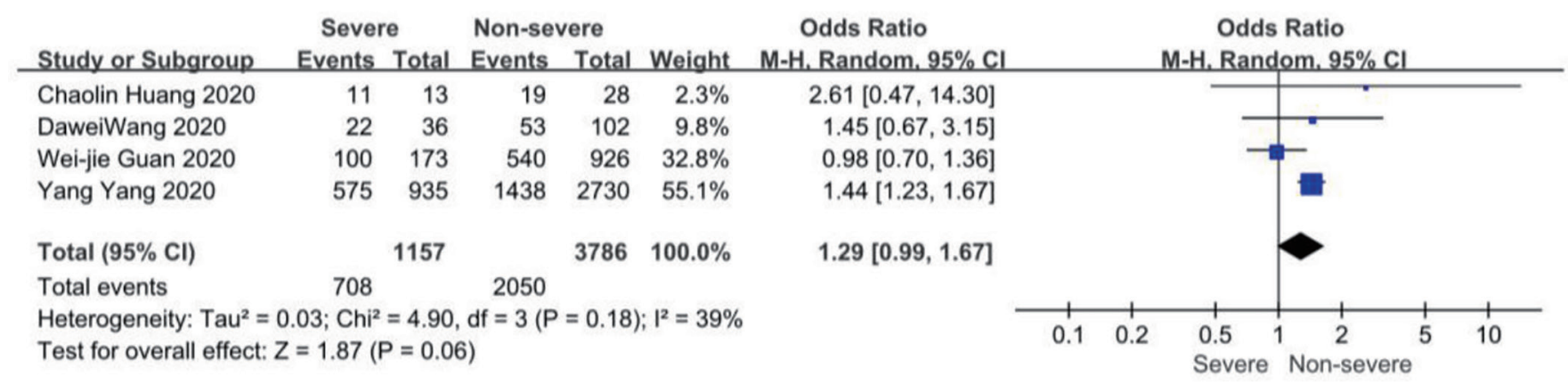

Figure S2 Forest plots of comparison severe versus non-severe cases for gender.

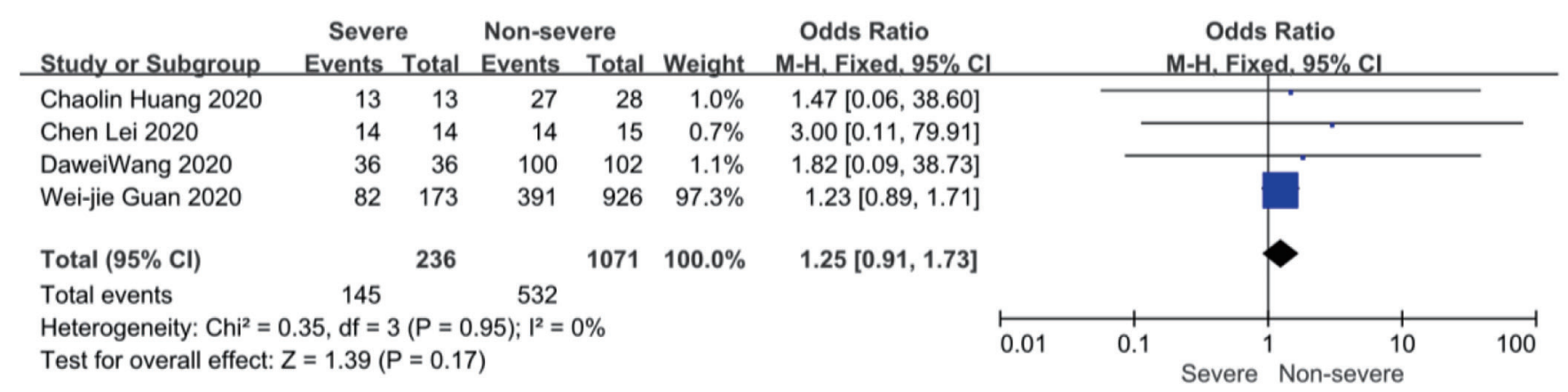

Figure S3 Forest plots of comparison severe versus non-severe cases for fever. 


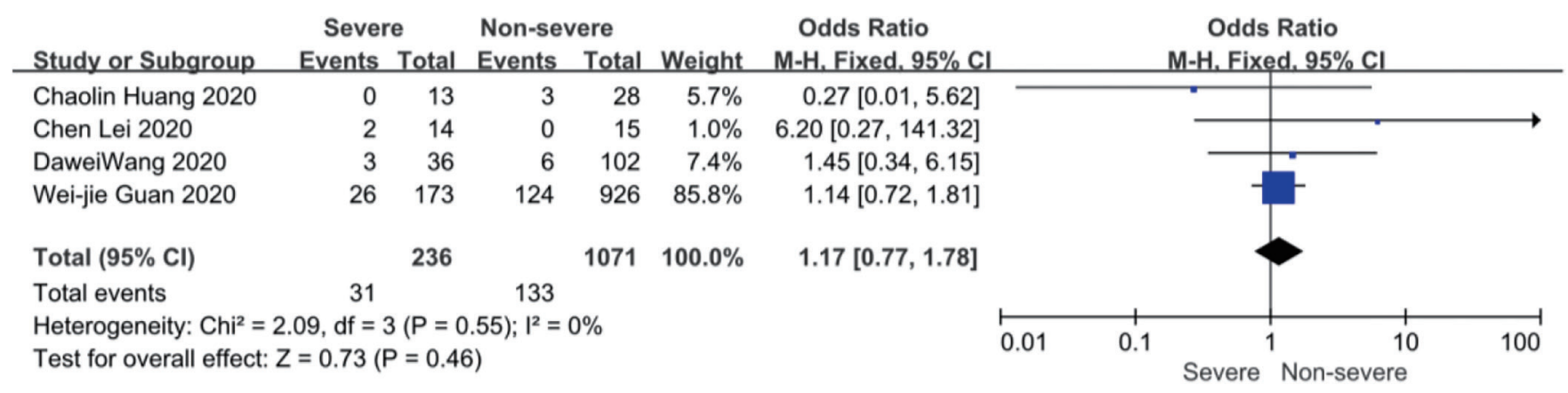

Figure S4 Forest plots of comparison severe versus non-severe cases for headache.

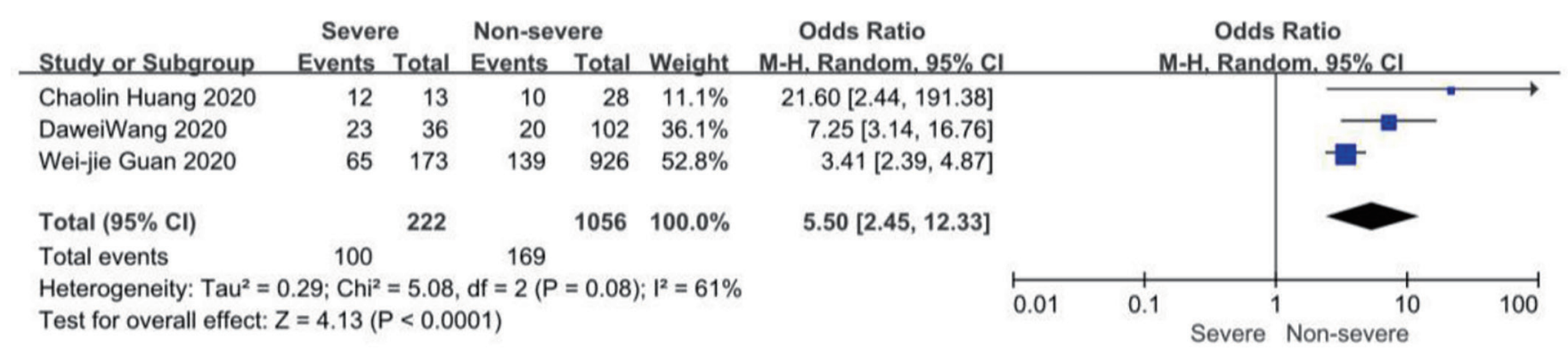

Figure S5 Forest plots of comparison severe versus non-severe cases for dyspnea.

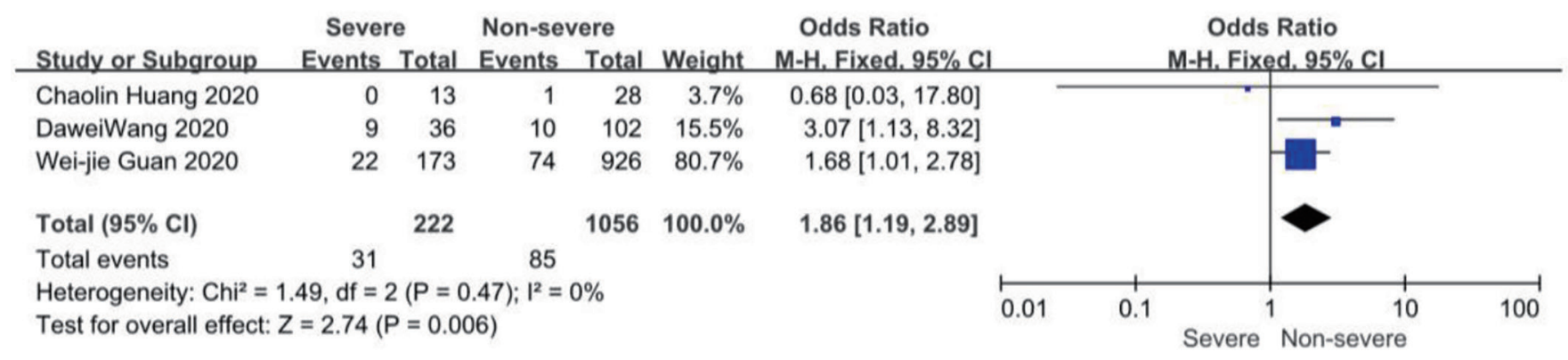

Figure S6 Forest plots of comparison severe versus non-severe cases for vomiting and diarrhea. 


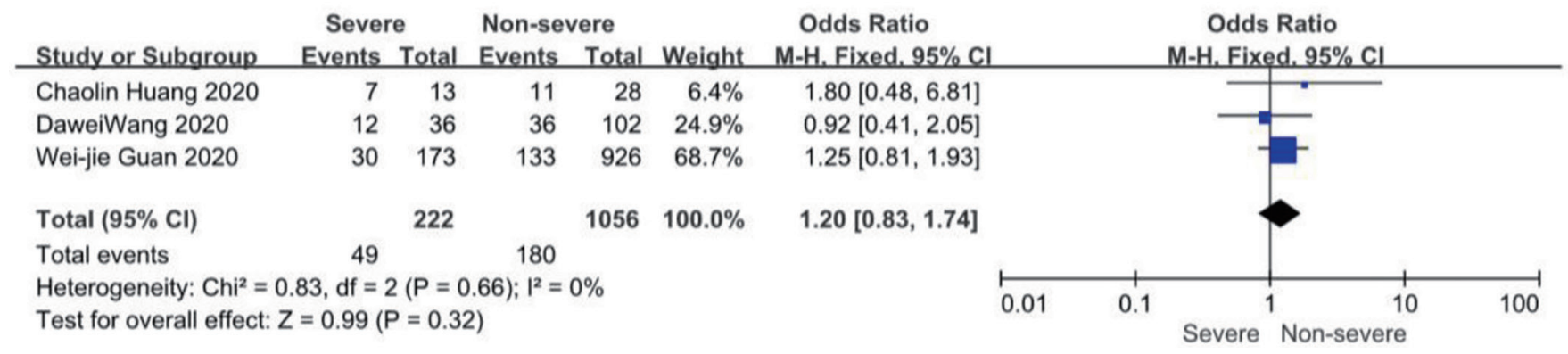

Figure S7 Forest plots of comparison severe versus non-severe cases for myalgia or arthralgia.

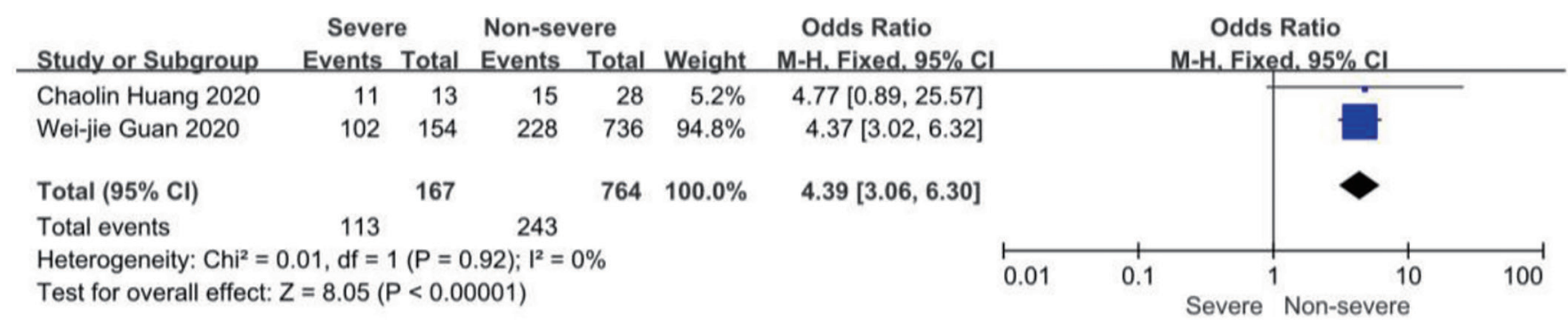

Figure S8 Forest plots of comparison severe versus non-severe cases for lymphocyte count $<1.5^{\star} 10^{\wedge} 9 / \mathrm{L}$.

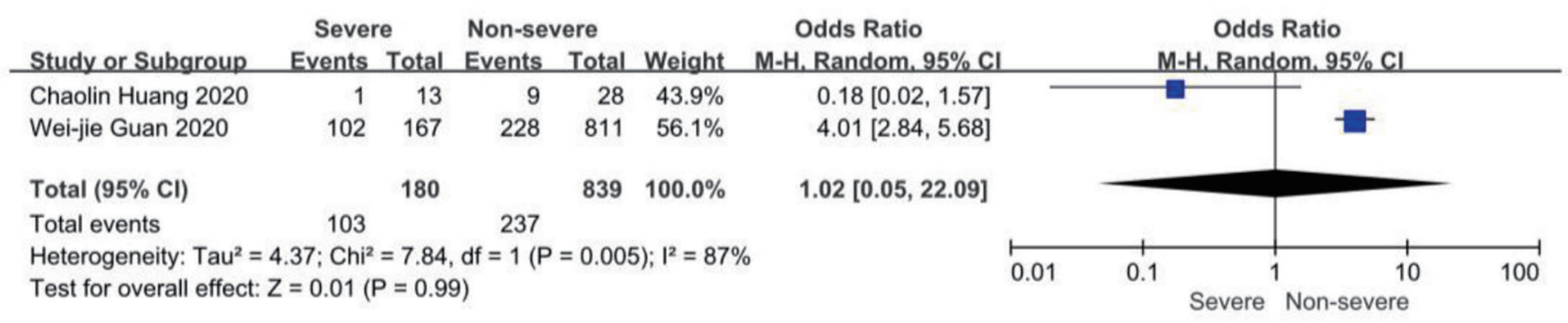

Figure S9 Forest plots of comparison severe versus non-severe cases for white blood cell count $<4^{\star} 10^{\wedge} 9 / \mathrm{L}$.

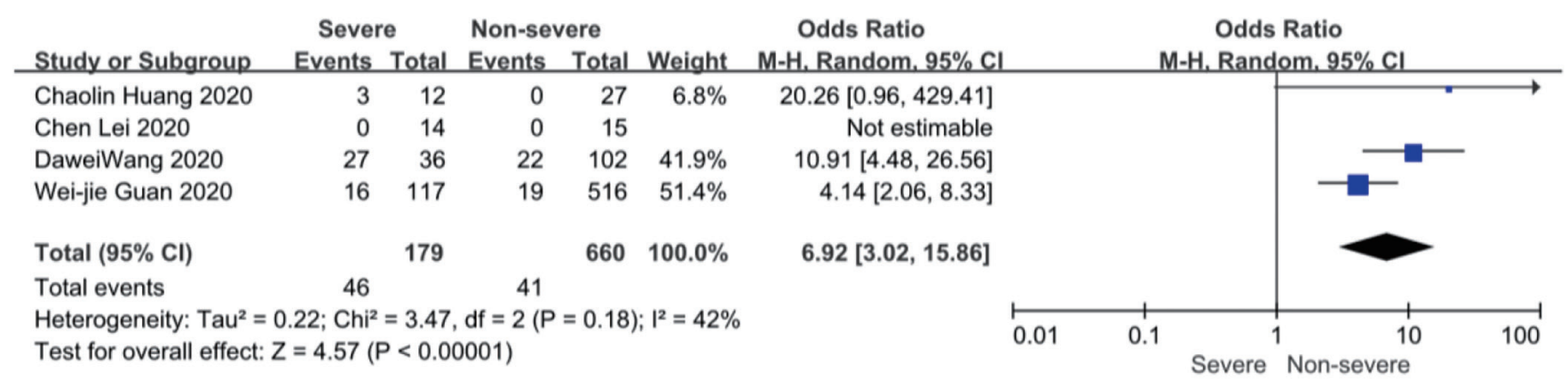

Figure S10 Forest plots of comparison severe versus non-severe cases for procalcitonin $\geq 0.05 \mathrm{ng} / \mathrm{mL}$. 


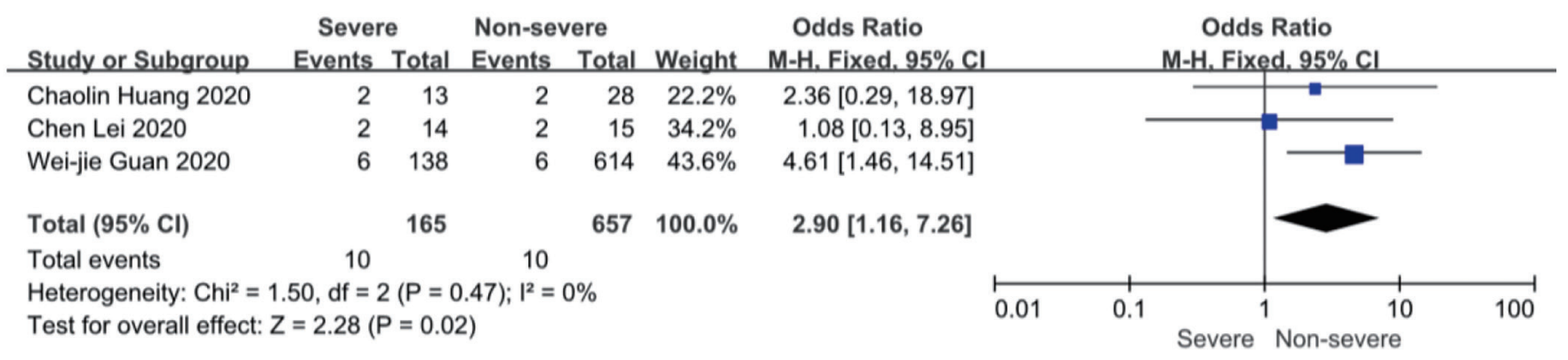

Figure S11 Forest plots of comparison severe versus non-severe cases for serum creatinine $>104 \mu \mathrm{mol} / \mathrm{L}$.

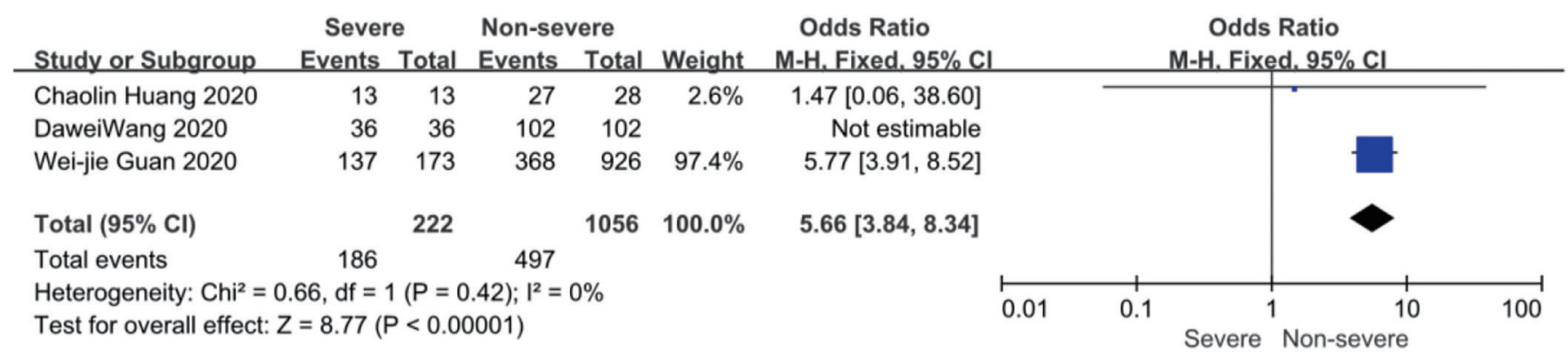

Figure S12 Forest plots of comparison severe versus non-severe cases for bilateral involvement of chest CT. 